\title{
Activity Based Learning Kits for Children in a Disadvantaged Community According to the Project "Vocational Teachers Teach Children to Create Virtuous Robots from Garbage"
}

\author{
Kuntida Thamwipat, Pornpapatsorn Princhankol, Thanakarn Khumphai and Vitsanu Sudsangket \\ Faculty of Industrial Education and Technology \\ King Mongkut's University of Technology Thonburi \\ Bangkok, Thailand
}

\begin{abstract}
This research was aimed to develop and evaluate the activity based learning kits for children in a disadvantaged community according to the project "Vocational Teachers Teach Children to Create Virtuous Robots from Garbage", to examine the learning achievement, to measure the satisfaction and to do an authentic assessment of children as regards the learning kits. The researchers chose the sampling group purposively out of children aged 4-14 years in the community under bridge zone 1 who could participate in the summer activity in the academic year 2013. The sampling group consisted of 40 children. Statistical tools in this research included mean and standard deviation. The results showed that the content quality was $\operatorname{good}(\bar{x}=4.40$, S.D. $=0.55)$, the presentation quality $\operatorname{was} \operatorname{good}(\bar{x}=4.46$, S.D. $=0.68)$. After learning with the learning kits, the children in the disadvantaged community could achieve higher post-test score than pre-test score with statistical significance at a .05 level. The children expressed the highest level of satisfaction towards the learning kits $(\bar{x}=4.57$, S.D. $=0.58)$. The authentic assessment of children as regards the learning kits was at a good level $(\bar{x}=4.43$, S.D. $=0.51$ and this complied with the hypotheses. Therefore, the activity based learning kits are useful and could be used in other nearby communities.
\end{abstract}

Keywords-Activity Based Learning Kits; Children in a Disadvantaged Community; Virtuous Robots; Garbage

\section{BACKGROUND}

In 1993, the cabinet decided to improve the living condition of people who live under the bridges in Bangkok and metropolitan areas because they are homeless. Bangkok Metropolitan Administration in collaboration with National Housing Authority provided over 700 families with home around the areas. The area called "Community under the Bridge Zone 1" is located around 10 kilometres away from King Mongkut's University of Technology Thonburi. At the moment there are around 200 families and the majority or $70 \%$ of the population is itinerant junk buyers. According to an interview with the community chief $\mathrm{Mr}$ Chaloermsak Leewangsee [1], one of the concerns in this community is that during the time of work the parents do not have time to look after their children because they gather together to play with garbage which can be dangerous without awareness such as firecrackers and fireworks, resulting in accidents. When the problem was taken into consideration, it was found that the main cause is that the children or the youth did not have space for recreation or activities and they lacked a good instructor. Therefore, they tended to use force or end a dispute through fights. They also did not appreciate the value of formal education, resulting in a low number of people who study beyond compulsory education.

According to the Public Welfare Education Development Plan for 5 Years (2012-2016), all disadvantaged children have a right and an opportunity to study compulsory education in accordance to their identity, maintain the quality of education through virtues and appreciation of Thai culture, and lead a life according to the self-sufficiency philosophy in the society for a happy life. According to the Office of the Education, Religion, Arts and Culture Commission, which have conducted many studies on behaviours among children and youths in relation to other people and communities [2], it was found that there is an increase in children and youth who display lack of virtues and moral conducts. Unless all the groups involved in solving the problem during the primary education, the nation could encounter serious problems when they grow up. Therefore, it is important to develop students with good character.

According to the problem and the significance mentioned above, the researchers decided to develop the activity based learning kits for children in a disadvantaged community according to the project "Vocational Teachers Teach Children to Create Virtuous Robots from Garbage" to mirror 8 kinds of virtues as follows: diligence, thrift, honesty, discipline, politeness, cleanliness, harmony, and generosity. Boonkuea Kuanhawet [3] says that learning kits are a kind of teaching material which is developed according to and consisted of topics, contents and experiences in each unit as part of a series for 3 stages: instruction, creation, promotion.

The researchers have been doing research in the community since 2011 and this year we were interested in the development of the activity based learning kits for children during the summer of the academic year 2013. 


\section{RESEARCH OBJECTIVES}

A. To develop and evaluate the activity based learning kits for children in a disadvantaged community according to the project "Vocational Teachers Teach Children to Create Virtuous Robots from Garbage"

B. To examine the learning achievement of children who use the activity based learning kits for children in a disadvantaged community according to the project "Vocational Teachers Teach Children to Create Virtuous Robots from Garbage”

C. To measure the satisfaction of children towards the activity based learning kits for children in a disadvantaged community according to the project "Vocational Teachers Teach Children to Create Virtuous Robots from Garbage"

D. To do an authentic assessment of children who use the activity based learning kits for children in a disadvantaged community according to the project "Vocational Teachers Teach Children to Create Virtuous Robots from Garbage”

\section{RESEARCH SCOPE}

The institution responsible for the project consists of the researchers and students at Faculty of Industrial Education and Technology, King Mongkut's University of Technology Thonburi

There were 2 periods of research as follows:

Preparation Period: from 1 December 2013 to 30 January 2014

Project Period: from 1 February 2014 to 30 May 2014

This project follows 3 stages of operation as in instructioncreation-promotion.

\section{POPULATION AND THE SAMPLING GROUP}

The population in this research consisted of 110 children in the community under the bridge zone 1 at Pracha Uthid 76 Road who were 4-14 years of age [1]. The researchers chose the sampling group purposively out of those who could participate in the summer activity. There were 40 children in total.

\section{RESEARCH HYPOTHESES}

A. The quality of the activity based learning kits for children in a disadvantaged community according to the project "Vocational Teachers Teach Children to Create Virtuous Robots from Garbage" would be at a good level.

B. The learning achievement of the children who use the activity based learning kits for children in a disadvantaged community according to the project "Vocational Teachers Teach Children to Create Virtuous Robots from Garbage" would show higher post-test score than pre-test score with statistical significance at the .05 level.

C. The satisfaction of the children towards the activity based learning kits for children in a disadvantaged community according to the project "Vocational Teachers
Teach Children to Create Virtuous Robots from Garbage" would be at a high level.

D. The authentic assessment of the children who use the activity based learning kits for children in a disadvantaged community according to the project "Vocational Teachers Teach Children to Create Virtuous Robots from Garbage” would be at a good level.

\section{TOOLS FOR DATA COLLECTION}

Tools in this research consisted of the quality evaluation form for the experts in contents and presentation learning activities for children, the learning achievement test, the children satisfaction questionnaire and the authentic assessment form.

\section{Statistical Methods Used}

The statistical methods in this research were Mean and Standard Deviation.

\section{RESEARCH RESULTS}

The results from the development and the evaluation of the quality of the activity based learning kits for children in a disadvantaged community according to the project "Vocational Teachers Teach Children to Create Virtuous Robots from Garbage" could be seen as follows:

TABLE I. THE PROCESS OF DEVELOPMENT FOR THE ACTIVITY BASED LEARNING KITS FOR CHILDREN IN A DISADVANTAGED COMMUNITY ACCORDING TO THE PROJECT "VOCATIONAL TEACHERS TEACH CHILDREN TO CREATE VIRTUOUS ROBOTS FROM GARBAGE"

\begin{tabular}{|l|l|l|l|}
\hline \multicolumn{1}{|c|}{ Step } & \multicolumn{1}{|c|}{ Researchers } & \multicolumn{1}{c|}{ Outcome } & Resource \\
\hline $\begin{array}{l}\text { Promoting the } \\
\text { new project } \\
\text { within the } \\
\text { community }\end{array}$ & $\begin{array}{l}\text { Creating } \\
\text { pamphlets and } \\
\text { visiting the } \\
\text { community }\end{array}$ & $\begin{array}{l}\text { Community } \\
\text { was informed of } \\
\text { the project and } \\
\text { well-prepared } \\
\text { for the activities }\end{array}$ & \\
\hline $\begin{array}{l}\text { Visiting the } \\
\text { area and } \\
\text { teaching the } \\
\text { children in the } \\
\text { disadvantaged } \\
\text { community } \\
\text { according to the } \\
\text { activity based } \\
\text { learning kits } \\
\text { for 10 weeks }\end{array}$ & $\begin{array}{l}\text { Visiting the area } \\
\text { and implementing } \\
\text { the research } \\
\text { through video } \\
\text { clips, plays, } \\
\text { storytelling, } \\
\text { painting, } \\
\text { excursion and } \\
\text { basic robot } \\
\text { creation }\end{array}$ & $\begin{array}{l}\text { Children in the } \\
\text { community } \\
\text { could create } \\
\text { their robots } \\
\text { which have } 8 \\
\text { virtues as in } \\
\text { diligence, thrift, } \\
\text { honesty, } \\
\text { discipline, } \\
\text { politeness, } \\
\text { cleanliness, } \\
\text { harmony and } \\
\text { generosity. }\end{array}$ & 1.Instruction \\
\hline $\begin{array}{l}\text { Virtuous } \\
\text { Robots }\end{array}$ & $\begin{array}{l}\text { Researchers, } \\
\text { volunteers and } \\
\text { children in the } \\
\text { community create } \\
\text { the robots which } \\
\text { have } 8 \text { virtues for } \\
\text { children in the } \\
\text { nursery }\end{array}$ & $\begin{array}{l}\text { Robots have } 8 \\
\text { virtues }\end{array}$ & 2. Creation \\
\hline
\end{tabular}




\begin{tabular}{|l|l|l|c|}
\hline \multicolumn{1}{|c|}{ Step } & \multicolumn{1}{|c|}{ Researchers } & \multicolumn{1}{c|}{ Outcome } & Resource \\
\hline $\begin{array}{l}\text { Distributing the } \\
\text { projects through } \\
\text { TV, free TV } \\
\text { channels and } \\
\text { national } \\
\text { newspaper }\end{array}$ & $\begin{array}{l}\text { Presenting the } \\
\text { virtuous robots } \\
\text { created by } \\
\text { children in the } \\
\text { disadvantaged } \\
\text { community }\end{array}$ & $\begin{array}{l}\text { Children build } \\
\text { up their self- } \\
\text { esteem through } \\
\text { sharing their } \\
\text { experiences } \\
\text { with the main } \\
\text { media }\end{array}$ & 3.Promotion \\
\end{tabular}

TABLE II. THE QUALITY EVALUATION OF THE ACTIVITY BASED LEARNING KITS ACCORDING TO THE EXPERT PANEL IN CONTENTS.

\begin{tabular}{|l|c|c|c|}
\hline \multicolumn{1}{|c|}{ Item } & $\overline{\boldsymbol{x}}$ & S.D. & Meaning \\
\hline 1.The contents about 8 virtues & 4.33 & 0.80 & Good \\
\hline 2. The presentation and activities & 4.20 & 0.50 & Good \\
\hline 3. The evaluation form & 4.67 & 0.35 & Very Good \\
\hline \multicolumn{1}{|c|}{ Overall } & $\mathbf{4 . 4 0}$ & $\mathbf{0 . 5 5}$ & Good \\
\hline
\end{tabular}

The mean score of the content quality was 4.40 on average with standard deviation of 0.55 . When this value was compared to the criteria, it was at a good level, or supporting the hypothesis.

TABLE III. THE MEAN SCORE FOR THE QUALITY OF ACTIVITY BASED LEARNING KITS AS EVALUATED BY THE EXPERT PANEL IN PRESENTATION

\begin{tabular}{|l|c|c|c|}
\hline \multicolumn{1}{|c|}{ Item } & $\overline{\boldsymbol{x}}$ & S.D. & Meaning \\
\hline 1.Content and activity presentation & 4.28 & 0.57 & Good \\
\hline 2. Activity step 1: Instruction & 4.44 & 0.85 & Good \\
\hline 3. Activity step 2: Creation & 4.65 & 0.50 & Very Good \\
\hline 4. Activity step 3: Promotion & 4.41 & 0.69 & Good \\
\hline $\begin{array}{l}\text { 5. Linking activities from each } \\
\text { learning unit }\end{array}$ & 4.52 & 0.81 & Very Good \\
\hline \multicolumn{1}{|c|}{ Overall } & $\mathbf{4 . 4 6}$ & $\mathbf{0 . 6 8}$ & Good \\
\hline
\end{tabular}

The mean score of the presentation quality was 4.46 with standard deviation of 0.68 . When the value was compared to the criteria, it was found to be at a good level, or supporting the hypothesis.

Photos below show the activity based learning kits for children in the disadvantaged community according to the project "Vocational Teachers Teach Children to Create Robots from Garbage" in relation to the 3 stages.

\section{A. Instruction}

Training for children in the disadvantaged community during the summer for 10 weeks
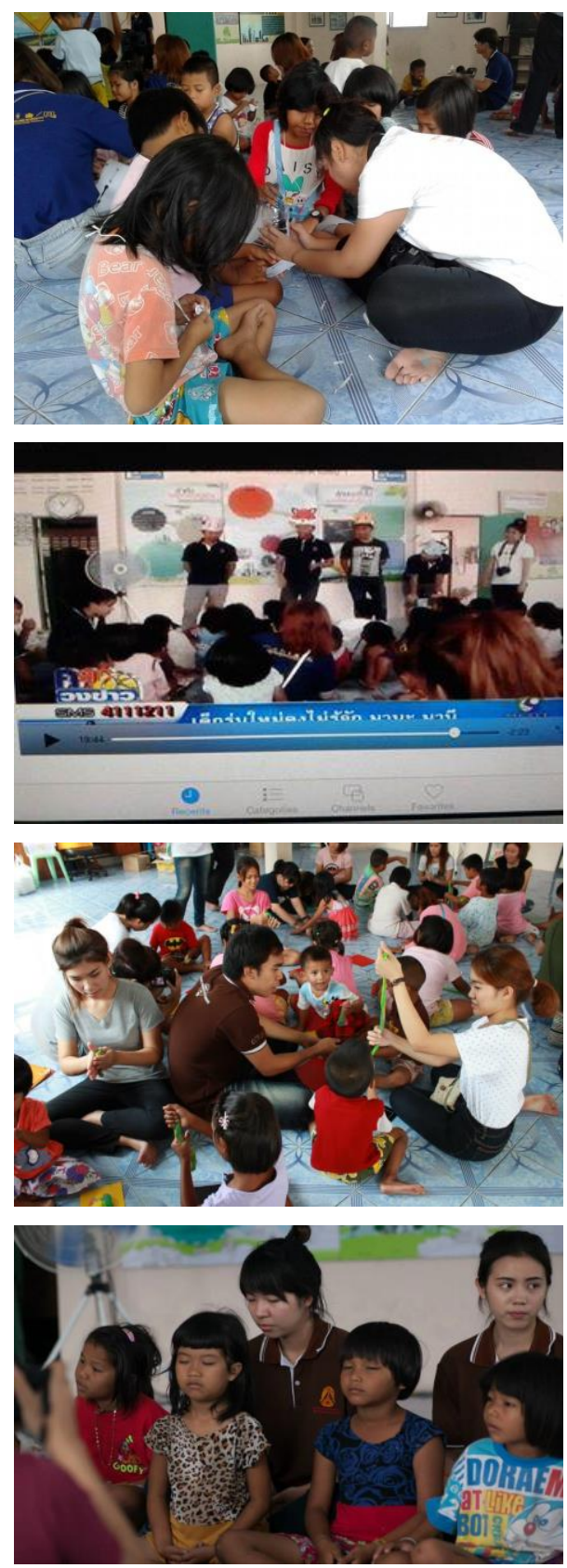

B. Creation

Robots with 8 virtues , 8 characters design

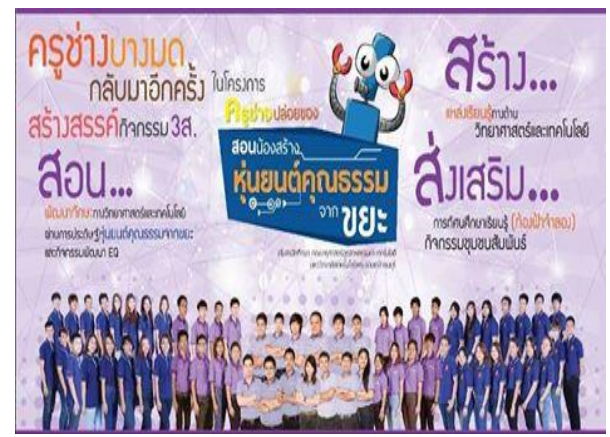



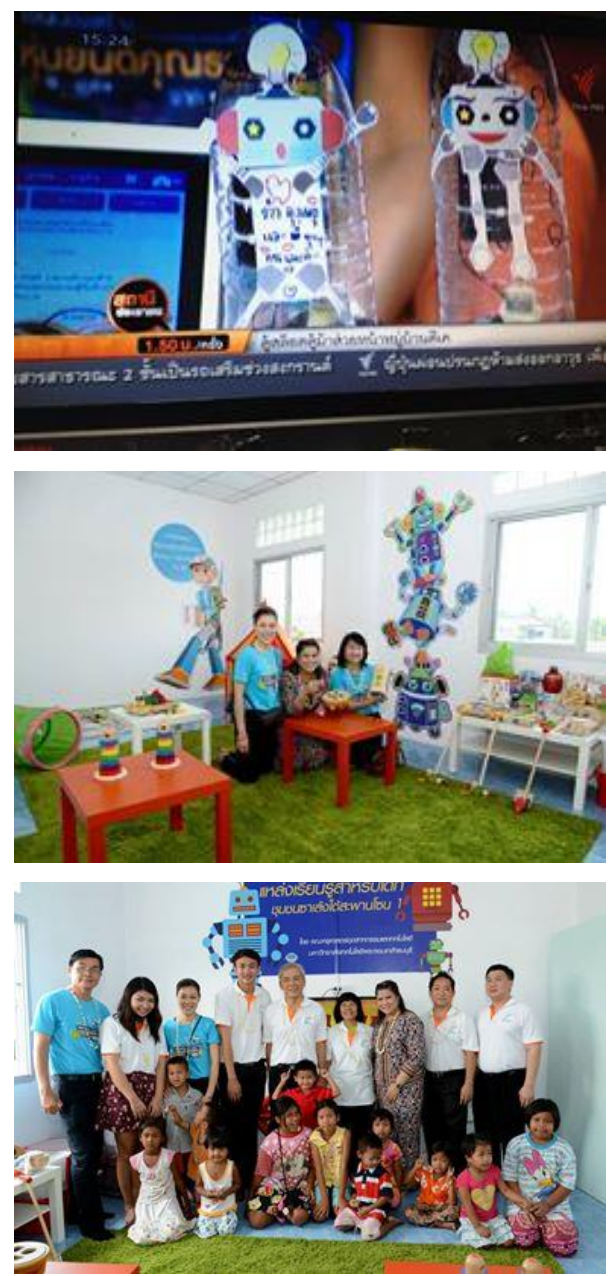

\section{Promotion}

Distribution of the projects through TV, free TV channels, and national newspaper

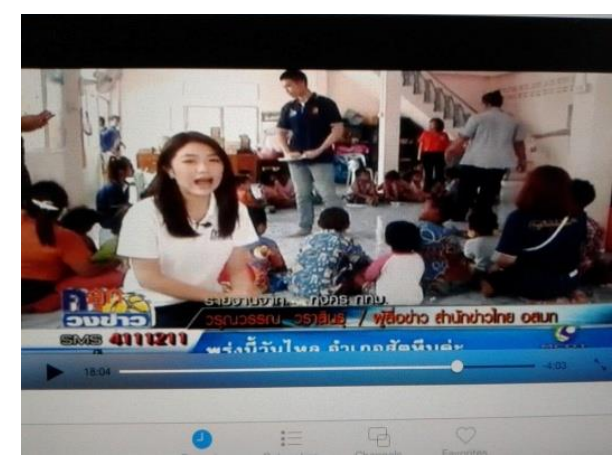

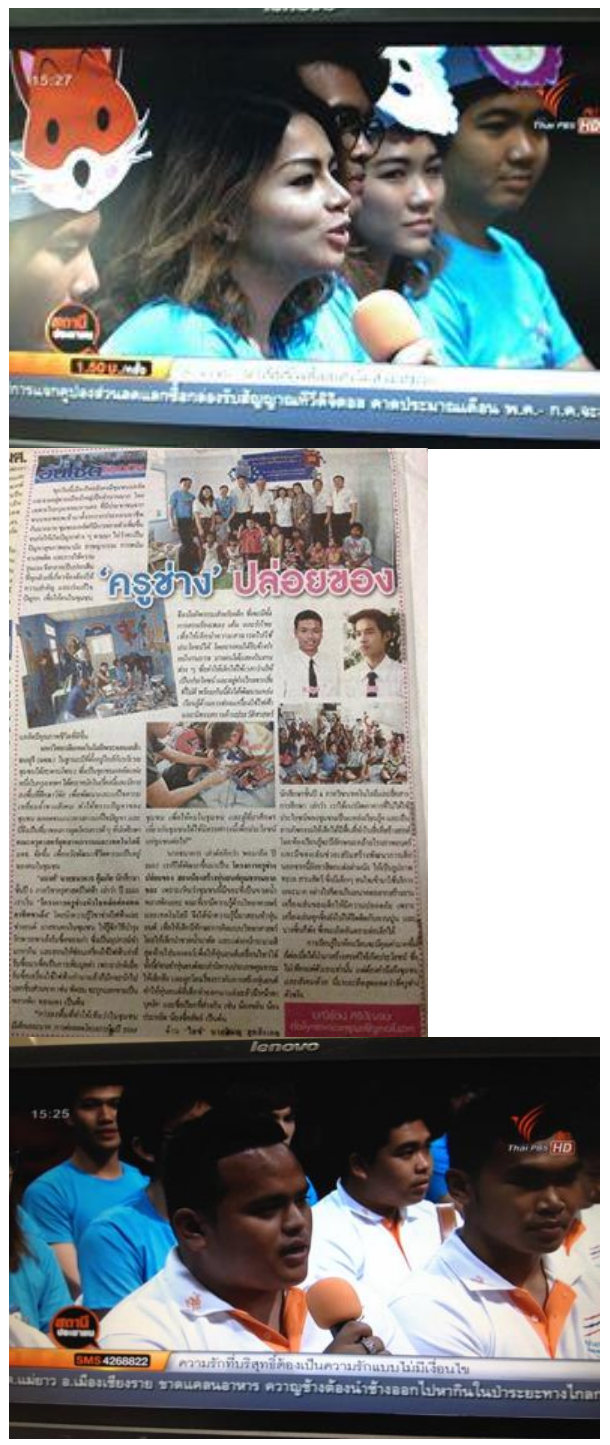

TABLE IV. THE LEARNING ACHIEVEMENT OF THE SAMPLING GROUP

\begin{tabular}{|ccccccc|}
\hline Test & $\mathbf{n}$ & $\overline{\boldsymbol{x}}$ & S.D. & $\overline{\mathbf{D}}$ & S.D.d & t \\
\hline Pre-test & 40 & 10.80 & 2.00 & 5.9 & 2.92 & $12.95^{*}$ \\
Post-test & 40 & 16.70 & 2.23 & & & \\
\hline
\end{tabular}

* with statistical significance at the .05 level

According to the research results, it was found that the children who use the activity based learning kits for children in a disadvantaged community according to the project "Vocational Teachers Teach Children to Create Virtuous Robots from Garbage" showed higher post-test score than pretest score with statistical significance at the .05 level, supporting the hypothesis. 
TABLE V. THE CHILDREN'S SATISFACTION TOWARDS THE ACTIVITY BASED LEARNING KITS FOR CHILDREN IN A DISADVANTAGED COMMUNITY ACCORDING TO THE PROJECT "VOCATIONAL TEACHERS TEACH CHILDREN TO CREATE VIRTUOUS ROBOTS FROM GARBAGE"

\begin{tabular}{|l|c|c|c|}
\hline \multicolumn{1}{|c|}{ Item } & $\overline{\boldsymbol{x}}$ & S.D. & Meaning \\
\hline 1.Content and activity presentation & 4.48 & 0.64 & High \\
\hline 2. Activity step 1: Instruction & 4.62 & 0.56 & The Highest \\
\hline 3. Activity step 2: Creation & 4.56 & 0.61 & The Highest \\
\hline 4. Activity step 3: Promotion & 4.62 & 0.56 & The Highest \\
\hline $\begin{array}{l}\text { 5. Benefits from activities in each } \\
\text { learning unit }\end{array}$ & 4.58 & 0.53 & The Highest \\
\hline \multicolumn{1}{|c|}{ Overall } & $\mathbf{4 . 5 7}$ & $\mathbf{0 . 5 8}$ & $\begin{array}{c}\text { The } \\
\text { Highest }\end{array}$ \\
\hline
\end{tabular}

The mean score for the children's satisfaction towards the activity based learning kits was 4.57 with standard deviation of 0.58 . When it was compared to the criteria, it was at the highest level.

TABLE VI. Shows THE MEAN SCORE OF THE Authentic AsSESSMENT OF CHILDREN AS REGARDS THE ACTIVITY BASED LEARNING KITS FOR ChILDREN IN A DisadVANTAGEd COMMUNITY ACCORDING TO THE PROJECT "Vocational TEACHERS TEACH CHILDREN to CREATE ViRTUOUS RoBOTS FROM GARBAGE"

\begin{tabular}{|c|c|c|c|}
\hline Item & $\bar{x}$ & S.D. & Meaning \\
\hline Authentic assessment of children & 4.43 & $\mathbf{0 . 5 1}$ & Good \\
\hline
\end{tabular}

The mean score of the authentic assessment in children as regards the activity based learning kits was 4.43 with standard deviation of 0.51 . When the value was compared with the criteria, it was at a good level, supporting the hypothesis.

\section{Disscussions}

This research into the activity based learning kits for children in a disadvantaged community according to the project "Vocational Teachers Teach Children to Create Virtuous Robots from Garbage" was considered to be of good quality in terms of contents with the mean score of 4.40 and standard deviation of 0.55 and of good quality in terms of presentation with the mean score of 4.46 and standard deviation of 0.68 . This was because the researchers adopted the principle proposed by Boonkuea Kuanhawet [3] along with the quality evaluation procedure for the learning kits as proposed by Wichai Wongyai [4] who put an emphasis on holistic thinking and attention by instructors for the development. The post-test score was higher than the pre-test score with statistical significance at the .04 level, supporting the hypothesis. This was in compliance with the research by Parinya Ubonkarn [5] who conducted a study into the development of games-based activities for mathematical preparation among primary school students at Thairat Wittaya 22 School (Tai Rom Yen) and showed similar level of learning achievement.
In terms of satisfaction, the children in this study expressed the highest level of satisfaction with the mean score of 4.57 and standard deviation of 0.58 . The mean score of the authentic assessment for children as regards the activity based learning kits was 4.43 with standard deviation of 0.51 , or at a good level and this supported the hypothesis. This was because the children in the study had many opportunities to learn and create their own works in accordance with the steps provided by the researchers in relation to the principle by Skinner [6] in that allowing learners to have freedom in thinking could lead to satisfaction towards learning.

\section{SugGestions}

A. The research into the activity based learning kits for children in a disadvantaged community according to the project "Vocational Teachers Teach Children to Create Virtuous Robots from Garbage" was of good quality. Therefore, this project could be expanded to other nearby communities such as the community behind Thonburi Rom Park.

$B$. The research results showed that the learners showed the highest level of satisfaction towards the activity steps from instruction, creation to promotion. In this research, student volunteers worked closely with the researchers in each step. Therefore, in the future activities, there should be an announcement to ask for student volunteers to participate in activities to improve disadvantaged communities.

\section{ACKNOWLEDGMENT}

The researchers would like to extend the gratitude to the funding by King Mongkut's University of Technology Thonburi and Red Bull U-Project.

\section{REFERENCES}

[1] Chaloermsak Leewangsee, Community Chief of Community under the Bridge Zone 1 at Pracha Utit 76 Road, Interview, 15 April 2013

[2] Office of the Education, Religion, Arts and Culture Commission, 2005, Projects to Improve Virtues and Moral Conducts of Students. The Secretariat of the Senate Printing House, Bangkok, p. 35.

[3] Boonkuea Kuanhawet. 1999. Educational Innovation . Chulalongkorn University Press, Bangkok, p. 40.

[4] Wichai Wongyai. 1982. Curriculum Development and Instruction: A New Dimension. Suweeriyasarn. Bangkok, p. 123.

[5] Parinya Ubonkarn. 2011. The Development of Games-Based Activities for Mathematical Preparation among Primary School Students at Thairat Wittaya 22 School (Tai Rom Yen), a Master's dissertation in Industrial Education, King Mongkut's University of Technology Thonburi, p.174.

[6] Skinner, BF..1971 . Beyond Freedom and Dignity. Toronto . A Bantam Vintage Boo, p. 127. 